\title{
A Young Man with Left Renal Mass - A Case of Primary Renal Lymphoma
}

\author{
MD. TITU MIAH, ${ }^{1}$ BI NOY KRI SHNA TARAFDER, ${ }^{2}$ AMI RUZZAMAN, DOSTH MOHAMMAD LUTFUR RAHMAN, \\ MUHAMMAD EHASUN UDDIN KHAN, ${ }^{5}$
}

\begin{abstract}
:
Renal involvement in lymphoma is not very uncommon but primary renal lymphoma is very rare and prognosis is poor. A 20 years male presented with localized, dull, constant pain and progressive swelling in left upper abdomen. He also gave history of significant weight loss. Examination findings revealed that he was anaemic, left kidney was hugely enlarged and hepatomegaly. Initially it seemed to be a case of renal cell carcinoma. But after doing invasive investigations it was proved to be a case of lymphoma, which considering all clinical and laboratory findings was diagnosed as a case of primary renal lymphoma.

Keywords: Young man, Primary, Renal mass, Lymphoma
\end{abstract}

\section{Introduction:}

Renal involvement in lymphoma is not very uncommon. Probably the exact incidence of the condition is underestimated as most cases are asymptomatic and less sensitive to conventional investigations like ultrasonography or intravenous urography. Autopsy studies shows that secondary involvement of kidney occurs in $50 \%$ of patients with lymphoma. ${ }^{1}$ This condition is most common in non-Hodgkin's than Hodgkin's lymphoma. Involvement of kidney may occur by haematogenous dissemination of systemic disease or contiguous spread from retroperitoneal disease. It has an insidious clinical presentation that occurs late in the course of disease. ${ }^{2,3}$

Sometimes it may be detected during follow up after giving specific treatment when patient is in remission. ${ }^{4}$ Very rarely it can also be involved as primary organ. Though primary renal lymphoma as a clinical entity has been disputed initially because kidney do not contain any lymphatic tissue, but there are some reported cases. ${ }^{4-8}$ It is a rare condition, comprising only $0.1 \%$ of renal lymphoma. ${ }^{8}$ The term is used when the initial manifestation involves kidney or the lesion is limited to it. ${ }^{3}$ The pathogenesis of primary renal lymphoma is poorly understood. Some investigators believe that lymphoma in non lymphoid organ arise in the setting of an inflammatory disease with a lymphoplasmacytic infiltrate. ${ }^{9}$ However such explanation has not been applied for kidney. It usually occurs in middle aged people and has slight male predominance. ${ }^{6}$ Clinical presentation includes flank pain, symptoms of renal insufficiency due to obstruction, haematuria and fever. ${ }^{3,10,11}$ In the series studied by Dimopoulos et al, all of 6 patients presented with urinary symptom without any peripheral lymph node enlargement. ${ }^{3}$ It disseminate rapidly from their renal origin. ${ }^{12} \mathrm{CHOP}$ regimen is the standard treatment and rituximab may be added. ${ }^{8}$ Survival is extremely poor, $75 \%$ of patients die in less than 1 year. ${ }^{12,13}$ Early detection of disease and initiation of systemic chemotherapy may improve survival.

\section{Case report:}

A20 year-old male garments worker from Tangail was admitted in medicine unit, Mymensingh Medical College Hospital with a 15 day history of dull, constant, localized pain and rapidly progressive swelling in the left upper abdomen. His appetite was reduced and lost weight approximately $5 \mathrm{~kg}$. He had history of low grade fever for few days before the onset of pain and swelling. He had no urinary complaint and bowel habit was normal. He did not give any history of vomiting, cough, respiratory distress, jaundice or itching. He did not have any history of TB or contact with known TB patient. He consulted local doctors and was prescribed analgesics with partial relief of pain. He was a smoker for 3 years, no $\mathrm{H} /$ O sexual exposure and family history was insignificant.

On examination, he was ill looking, nutritional status was below average, mildly anaemic, non icteric, pulse 72 beat/ min, BP 125/80mmHg, temperature $98.6^{0} \mathrm{~F}$. Left kidney was hugely enlarged, tender, firm with irregular surface. Liver

1. Assistant Professor, Department of Medicine, Dhaka Medical College Hospital

2. Registrar, Cardiology, Sir Salimullah Medical College, Mitford Hospital

3. Resident Physician, Sir Salimullah Medical College, Mitford Hospital

4. Indoor Medical Officer, Department of Radiology \& Imaging, Dhaka Medical College Hospital

5. Registrar, Medicine, Sir Salimullah Medical College, Mitford Hospital

Correspondence: Md. Titu Miah, Assistant Professor, Department of Medicine, Dhaka Medical College Hospital 
was enlarged, $3 \mathrm{~cm}$ from right subcostal margin along mid clavicular line, nontender, firm with irregular surface. Other systemic examination reveals no abnormality.

On investigation, WBC - 7800/ $\mathrm{mm}^{3}$, neutrophil-68\%, lymphocyte-26\%, monocyte-02\%, eosinophil-04\%. Hb was $10.5 \mathrm{gm} / \mathrm{dl}$ and ESR-104 mm in 1st hour. Urine R/E, Chest X ray $\mathrm{P} / \mathrm{A}$ view was normal. Prothrombin time was $15 \mathrm{sec}$, SGPT $60 \mathrm{u} / \mathrm{l}$, Serum creatinine $0.8 \mathrm{mg} / \mathrm{dl}$. USG of whole abdomen revealed multiple SOL in liver, abdominal (para aortic) lymphadenopathy, enlarged heterogenous left kidney measuring $19 \times 14 \mathrm{~cm}$. USG guided FNAC was done from liver and left renal mass. Cytology of liver showed round cells malignancy consistent with lymphoma and left renal mass FNAC was consistent with large cell lymphoma. CT guided FNAC was done from left kidney mass for cytology and immunocytochemistry which showed B cell non-Hodgkin's lymphoma.

The patient was diagnosed as high grade $\mathrm{B}$ cell nonHodgkins lymphoma stage IVB. In fact, it was a case of primary renal lymphoma. He was treated with chemotherapy cylophosphamide, doxorubicin, vincristine, prednisolone for 8 cycle 4 weeks interval between each cycle and supportive treatments. Response was excellent initially though relapse occurred 7 months after the end of chemotherapy. Then he was referred to a specialized oncology centre.

\section{Discussion:}

We consider that this is a rare and important case for discussion in many points of view. The patient presented with very short history and initially considering all the clinical features it seemed to be a case of renal cell carcinoma with metastases to liver and paraaortic lymph node. But he was too young. We also considered disseminated tuberculosis and lymphoma as differential diagnoses. Tuberculosis is very common in our community. Moreover age and occupation of the patient, history of low grade fever, weight loss was in favour of tuberculosis. But duration of symptom was very short and there was no urinary complaint. After doing the initial noninvasive investigations including ultrasonography, we did not get any specific evidence of tuberculosis and we were also unable to reach a diagnosis. We did FNAC from the liver mass which showed evidence of lymphoma. Then we did FNAC from the renal mass to ensure the diagnosis revealed by liver FNAC. It was also consistent with large cell lymphoma. After doing immunocytochemistry of renal FNA, the patient was leveled as high grade non-Hodgkin's lymphoma stage IVB as there was diffuse renal and hepatic involvement and also systemic symptoms like fever, weight loss. Secondary renal involvement in non-Hodgkin's lymphoma is a late and insidious feature, sometimes occur during or after chemotherapy and mostly asymptomatic and usually diagnosed by CT or MRI or at autopsy. ${ }^{2-4}$ But our patient had presented with rapid onset of symptoms related to left renal mass and examining and investigating the patient also revealed huge renal mass and relatively small liver and paraaortic node enlargement indicating that left kidney is the primary organ involved and dissemination in liver and para aortic nodes. So we finally diagnosed the patient as a case of primary renal lymphoma. However treatment regimen will not vary on the diagnosis whether primary or secondary. Probably the only concern is dilemma in diagnosis and prognosis. In some similar cases the suspicion of primary renal lymphoma was not even kept and patient was diagnosed after undergoing unnecessary nephrectomy and histopathology. ${ }^{13,14}$ Most of the reported primary cases had rapid systemic progression and survived less than a year. ${ }^{4,12}$ Our patient responded initially very well to intensive chemotherapy though relapse occurred very soon and ultimate prognosis could not be known. As the patient did not followup.

\section{Conclusion:}

Our case is a rare one as very few like it was reported before. Another thing is, in any patient with unilateral renal mass, along with the diagnosis renal cell carcinoma, we should keep lymphoma also as a differential diagnosis particularly in atypical group. It may prevent unnecessary renal surgery and specific therapy can be started without delay.

\section{Conflict of Interest: None}

\section{References:}

1. Kandel LB, McCullough DL, Harrison LH, Woodruff RD, Ahl ET Jr, Munita HA. Primary renal lymphoma. Does it exist? Cancer 1987;60:386-91

2. Urban BA, Fishman EK. Renal lymphoma: CT patterns with emphasis on helical CT. Radiographics 2000;20:197212

3. Dimopoulos MA, Moulopoulos LA, Costantinides C, Deliveliotis C, Pantazopoulos D, Dimopoulos C. Primary renal lymphoma: a clinical and radiological study. J Urol 1996;155:1865-7

4. Barreto F, Dall’Oglio MF, Srougi M. Renal lymphoma. Atypical presentation of a renal tumor. Int Braz J Urol 2006;32:190-2

5. Tefekli A, Baykal M, Binbay M, Barut M, Muslumanoglu AY. Lymphoma of the kidney: primary or initial manifestation of rapidly progressive systemic disease?. Int Urol Nephrol 2006;38(3-4):775-8

6. Gellrich J, Hakenberg OW, Naumann R, Manseck A, Lossnitzer A, Wirth MP. Primary renal non-Hodgkin’s 
lymphoma - a difficult differential diagnosis. Onkologie 2002;25(3):273-7

7. Stallone G, Infante B, Manno C, Campobasso N, Pannarale G, Schena FP. Primary renal lymphoma does exist: case report and review of the literature. J Nephrol 2000;13(5):36772

8. Pervez H, Shaikh M, Potti A, Mehdi SA. Uncommon presentation of non-Hodgkin's lymphoma. Case 3-primary renal lymphoma. Journal of clin oncology 2003;21(3):567-9

9. Brouland JP, Meeus F, Rossert J, Hernigou A, Gentric D, Jacquot C, et al. Primary bilateral B-cell renal lymphoma. Am J Kidney Dis 1994;24:586-9

10. Yaomura T, Hayashi H, Kanoh T, Kurata K, Ishihara S, Machida $\mathrm{H}$, et al. A case of non-Hodgkin's lymphoma presenting with acute renal failure diagnosed by renal biopsy. Nippon Jinzo Gakkai Shi 1999;41:505-10

11. Chin KC, Perry GJ. Primary T cell rich B-cell lymphoma in the kidney presenting with acute renal failure and a second malignancy. Pathology 1999;31:325-7

12. Saito S. Primary renal lymphoma: case report and review of literature. Urol Int 1996;56:192-5

13. Gupta A, Bhatt A, Khaira A, Gupta A, Ran DS. Primary renal lymphoma: a differential diagnosis of renal mass in a young male. Saudi J Kidney Dis Transpl 2010;21(3):544-5

14. Vazquez Alonso F, Sanchez Ramos C, Vicente Padros FJ, Pascual Geler M, Ruiz Carazo E, Becerra Massare P, et al. Primary renal lymphoma: report of three new cases and literature review. Arch Esp Urol 2009;62(6):461-5 